ARTICLE

DOI: $10.1038 / s 41467-018-04746-z$

\title{
High-performance bifunctional porous non-noble metal phosphide catalyst for overall water splitting
}

Fang Yu ${ }^{1,2}$, Haiqing Zhou ${ }^{1,2}$, Yufeng Huang ${ }^{3}$, Jingying Sun ${ }^{1}$, Fan Qin ${ }^{4}$, Jiming Bao ${ }^{4}$, William A. GoddardIII ${ }^{3}$, Shuo Chen ${ }^{1} \&$ Zhifeng $\operatorname{Ren}^{1}$

Water electrolysis is an advanced energy conversion technology to produce hydrogen as a clean and sustainable chemical fuel, which potentially stores the abundant but intermittent renewable energy sources scalably. Since the overall water splitting is an uphill reaction in low efficiency, innovative breakthroughs are desirable to greatly improve the efficiency by rationally designing non-precious metal-based robust bifunctional catalysts for promoting both the cathodic hydrogen evolution and anodic oxygen evolution reactions. We report a hybrid catalyst constructed by iron and dinickel phosphides on nickel foams that drives both the hydrogen and oxygen evolution reactions well in base, and thus substantially expedites overall water splitting at $10 \mathrm{~mA} \mathrm{~cm}^{-2}$ with $1.42 \mathrm{~V}$, which outperforms the integrated iridium (IV) oxide and platinum couple $(1.57 \mathrm{~V})$, and are among the best activities currently. Especially, it delivers $500 \mathrm{~mA} \mathrm{~cm}^{-2}$ at $1.72 \mathrm{~V}$ without decay even after the durability test for $40 \mathrm{~h}$, providing great potential for large-scale applications.

\footnotetext{
${ }^{1}$ Department of Physics and TcSUH, University of Houston, Houston, TX 77204, USA. ${ }^{2}$ Key Laboratory of Low-Dimensional Quantum Structures and Quantum Control of Ministry of Education, School of Physics and Electronics, Hunan Normal University, Changsha 410081, China. ${ }^{3}$ Materials and Process Simulation Center (139-74), California Institute of Technology, Pasadena, CA 91125, USA. ${ }^{\circ}$ Department of Electrical and Computer Engineering, University of Houston, Houston, TX 77204, USA. These authors contributed equally: Fang Yu, Haiqing Zhou. Correspondence and requests for materials should be addressed to S.C. (email: schen34@uh.edu) or to Z.R. (email: zren@uh.edu)
} 
T he scalable storage of such abundant renewable energy sources as wind or solar energy is required to mitigate the aggravated global energy crisis while addressing the environmental issues ${ }^{1}$. Converting solar- or wind-derived electricity to hydrogen fuel via water electrolysis is an appealing means to accomplish this energy conversion and storage technology ${ }^{2-6}$. At present, there are mainly two commercialized water electrolysis including alkaline and proton exchange membrane (PEM) water electrolysis. PEM water electrolysis has high energy efficiency with high hydrogen production rate, but requires noble metal platinum $(\mathrm{Pt})$ or iridium (Ir)-based catalysts, making it unfavorable due to high cost and scarcity. The alternative, low-cost alkaline water electrolysis, is a mature technology for large-scale hydrogen production that is low-cost due to compatibility with non-noble catalysts, but it suffers from low production rates ${ }^{9,10}$. One of its grand challenges remains to the huge energy penalty caused by the uphill reaction kinetics of the catalysts that requires significantly high cell voltages (1.8-2.4 $\mathrm{V}$, far larger than the thermodynamic value of $1.23 \mathrm{~V}$ ) to catalyze the reaction with electrolysis currents of $200-400 \mathrm{~mA} \mathrm{~cm}^{-2}$, resulting in the production of less than $5 \%$ hydrogen by means of water electrolysis in the worldwide industry ${ }^{18-12}$. Therefore, it is urgent to rationally develop exceptionally efficient nonnoble catalysts for expediting overall water splitting toward large-scale commercialization at high current densities with low cell voltages.

Currently, there exist some intriguing bifunctional catalysts to negotiate the overall water splitting efficiently in alkaline electrolytes, including transition-metal oxides (e.g., $\mathrm{MoO}_{2}$, $\left.\mathrm{NiCoO}_{4}\right)^{13-15}$, layered double hydroxides (LDH) (e.g., NiFe $\mathrm{LDHs})^{2,16}$, sulfides (e.g., $\left.\mathrm{NiCo}_{2} \mathrm{~S}_{4}, \mathrm{MoS}_{2} / \mathrm{Ni}_{3} \mathrm{~S}_{2}\right)^{17,18}$, selenides (e.g., $\mathrm{NiSe})^{19}$, and phosphides (e.g., $\mathrm{CoP}_{2} /$ reduced graphene oxide, $\left.\mathrm{Ni}_{5} \mathrm{P}_{4}\right)^{20,21}$. Unfortunately, most of them can operate only steadily at low current density $\left(<20 \mathrm{~mA} \mathrm{~cm}^{-2}\right)$, not to mention their low energy conversion efficiency at above 200 $\mathrm{mA} \mathrm{cm}{ }^{-2}$ required for commercial applications. These catalysts are far from being optimized for industrial scales ${ }^{10,22}$ probably arisen from the difficulty in integrating both the merits of hydrogen evolution reaction (HER) and oxygen evolution reaction (OER) electrocatalysts in a single bifunctional catalyst in the same electrolyte (either alkaline or acid). In this regard, constructing a single bifunctional catalyst with outstanding HER and OER activities simultaneously in the same electrolyte is urgently needed.

We report here, just such a cost-effective catalyst that we discover using the straightforward strategy of hybridizing two metallic iron and dinickel phosphides $\left(\mathrm{FeP} / \mathrm{Ni}_{2} \mathrm{P}\right)$ on commercial nickel $(\mathrm{Ni})$ foams. This produces an extremely active bifunctional electrocatalyst for both OER and HER outperforming most of the catalysts with similar function, and also exceptional overall water splitting surpassing commercial alkaline electrolyzers in $1 \mathrm{M} \mathrm{KOH}$. Specifically, we corroborate that our $\mathrm{FeP} / \mathrm{Ni}_{2} \mathrm{P}$ hybrid performs well for HER with catalytic performance $\left(-14 \mathrm{mV}\right.$ to achieve $\left.-10 \mathrm{~mA} \mathrm{~cm}^{-2}\right)$ as good as that of the state-of-the-art noble Pt catalyst $(-57 \mathrm{mV})$, and also for OER with the lowest overpotential $(154 \mathrm{mV}$ to afford $10 \mathrm{~mA} \mathrm{~cm}^{-2}$ ) reported thus far, substantially outperforming the benchmark $\mathrm{IrO}_{2}(281 \mathrm{mV})$ and other reported robust OER catalysts. Furthermore, inspired by the excellent HER and OER activity, we integrated this bifunctional catalyst directly as both the anode and cathode electrodes in an alkaline electrolyzer, and demonstrate that a cell voltage of only $1.42 \mathrm{~V}$ can deliver $10 \mathrm{~mA} \mathrm{~cm}^{-2}$, and a cell voltage of $1.72 \mathrm{~V}$ is required to deliver $500 \mathrm{~mA} \mathrm{~cm}^{-2}$ with $40 \mathrm{~h}$ durability, far surpassing the performance of current industrial catalysts, which require $2.40 \mathrm{~V}$ for $400 \mathrm{~mA} \mathrm{~cm}^{-2}$.

\section{Results}

Electrocatalyst preparation and characterization. Our $\mathrm{Fe}-\mathrm{Ni}-\mathrm{P}$ hybrid architecture was prepared directly on commercial $\mathrm{Ni}$ foams by a simple thermal treatment process. Typical scanning electron microscopy (SEM) images show that the as-prepared samples are free-standing with abundant mesopores and/or nanopores at the surface (Fig. la and b), indicating efficacious achievement of large surface areas for facile exchange of proton or oxygen-containing intermediates ${ }^{5,23}$. In particular, numerous nanocrystals are distributed uniformly at the surface, forming plentiful surface active sites in this hybrid catalyst. The selected area electron diffraction pattern (Fig. 1c), combined with highresolution transmission electron microscopy (TEM) images (Fig. 1d, Supplementary Fig. 1), further reveal the nanoscale features of the $\mathrm{FeP}$ and $\mathrm{Ni}_{2} \mathrm{P}$ particles with diameters of 5-30 nm. The interplanar spacings of these nanoparticles are resolved by TEM to be around 0.204 and $0.502 \mathrm{~nm}$ corresponding to the (021) and (010) planes of $\mathrm{Ni}_{2} \mathrm{P}$ crystals, and 0.181 and $0.193 \mathrm{~nm}$ corresponding to the (103) and (220) planes of FeP crystals. To determine the distribution of $\mathrm{Ni}, \mathrm{Fe}$, and $\mathrm{P}$ elements in the asprepared samples, elemental mapping was carried out using TEM, confirming the homogenous distribution of $\mathrm{Ni}, \mathrm{Fe}$, and $\mathrm{P}$ elements in the $\mathrm{FeP} / \mathrm{Ni}_{2} \mathrm{P}$ nanoparticles (Fig. 1e). The energy dispersive X-ray (EDX) spectrum (Supplementary Fig. 2) shows that the $\mathrm{Ni}, \mathrm{Fe}$, and $\mathrm{P}$ elements are present with an atomic ratio close to 2:1:2, consistent with the high-resolution TEM observations.

The chemical composition and oxidation states of the catalysts were further unveiled by X-ray photoelectron spectroscopy (XPS) and X-ray diffraction (XRD). The P $2 \mathrm{p}$ core level spectrum can be fit with two doublets (Fig. 1f), with one located at the binding energies of 129.3 and $130.1 \mathrm{eV}$ attributing to phosphorus anions of metal phosphides, and the other at 133.5 and $134.3 \mathrm{eV}$ indicative of phosphate-like $\mathrm{P}$ arisen from possible surface oxidation, as has been observed previously ${ }^{24-26}$. The XPS spectrum of Fe $2 p^{3 / 2}$ core level (Supplementary Fig. 3a) can be deconvoluted into three main peaks with binding energies of 707.0, 709.9, and $711.9 \mathrm{eV}$ assigned to FeP, Fe-based oxide, and phosphate, respectively, caused by possible superficial oxidation when exposing $\mathrm{FeP}$ samples to air ${ }^{26-28}$, while another peak located at $714.3 \mathrm{eV}$ is arisen from the relevant satellite peak. This peak deconvolution is also applied to the $\mathrm{Ni} 2 \mathrm{p}^{3 / 2}$ core level spectrum (Supplementary Fig. 3b), where three binding energies located at $853.6,856.4$, and $861.0 \mathrm{eV}$ are ascribed to $\mathrm{Ni}_{2} \mathrm{P}$, $\mathrm{Ni}-\mathrm{PO}_{x}$, and the corresponding satellite peak, respectively. These information means that both the $\mathrm{FeP}$ and $\mathrm{Ni}_{2} \mathrm{P}$ contribute to the overall signals with the binding energy at $129.3 \mathrm{eV}$ of $\mathrm{P} 2 \mathrm{p}^{3 / 2}$, even though it is difficult to distinguish the binding energy difference between these two compounds. According to the survey spectrum (Supplementary Fig. 4) and distribution quantification (Supplementary Table 1), it is estimated that the percentage of surface oxidized species in $\mathrm{FeP}$ nanoparticles is close to $74.8 \%$, and the percentage in $\mathrm{Ni}_{2} \mathrm{P}$ is around $13.5 \%$, which indicates that the original $\mathrm{Fe}-\mathrm{Ni}-\mathrm{P}$ samples are heavily oxidized at the surface. A typical XRD pattern (Fig. 1g) reveals the main indexes from the as-prepared $\mathrm{FeP} / \mathrm{Ni}_{2} \mathrm{P}$ hybrid and $\mathrm{Ni}$ foam support. The two strongest peaks at $45^{\circ}$ and $52^{\circ}$ are mainly originated from the Ni foam support (ICSD-53809). All the other peaks are the characteristic ones of $\mathrm{FeP}$ (ICSD-633046) and $\mathrm{Ni}_{2} \mathrm{P}$ (ICSD-646102), consistent with our TEM analysis.

Oxygen evolution catalysis. We first evaluated the catalytic OER activity of this $\mathrm{Fe}-\mathrm{Ni}-\mathrm{P}$ hybrid catalyst in $1.0 \mathrm{M} \mathrm{KOH}$ electrolyte ${ }^{6,29}$. Representative polarization curves in Fig. $2 \mathrm{a}$ and $\mathrm{b}$ show the geometric current density plotted against applied potential vs reversible hydrogen electrode (RHE) of this $\mathrm{Fe}-\mathrm{Ni}-\mathrm{P}$ hybrid 

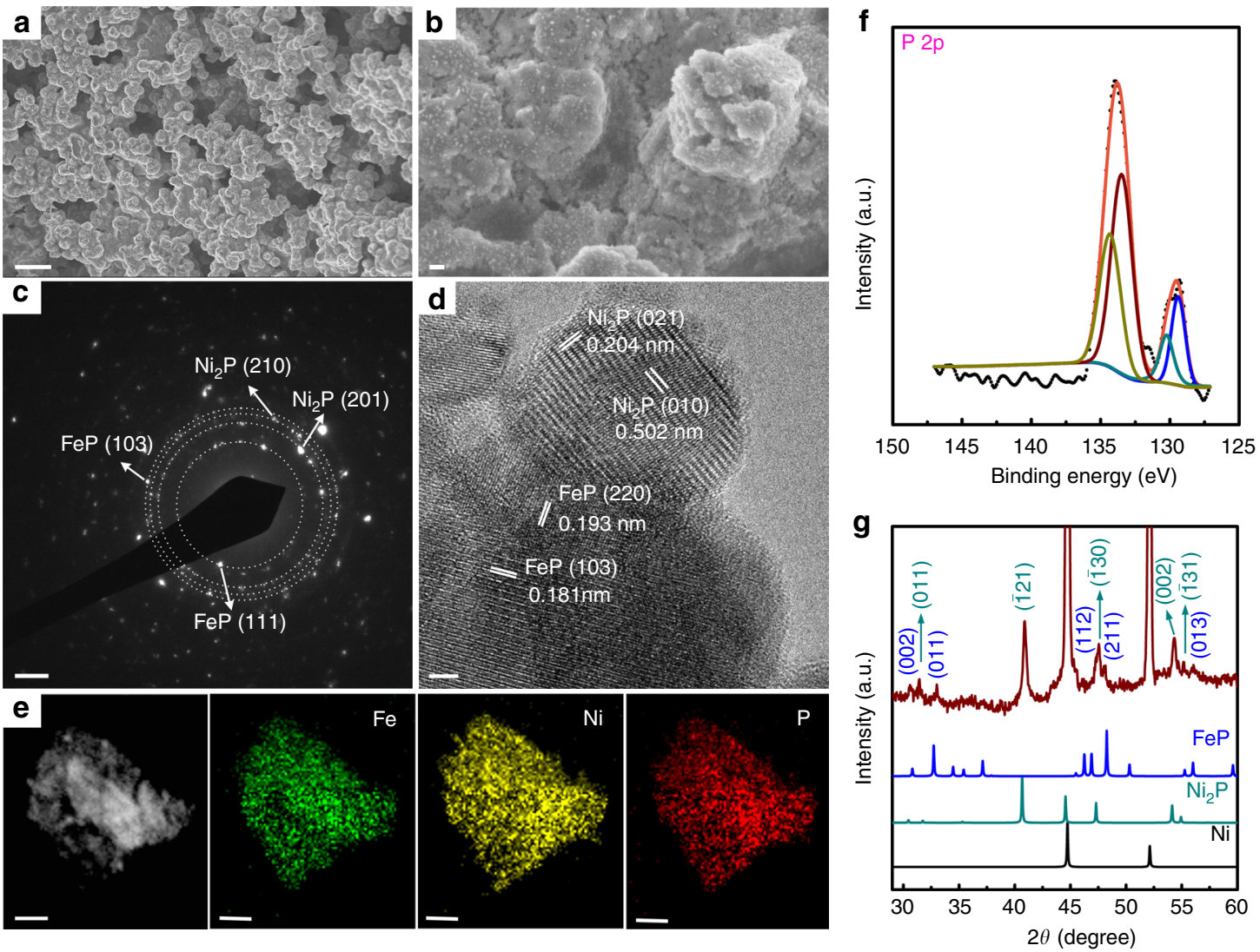

Fig. 1 Synthesis and microscopic characterization of as-prepared FeP/Ni 2 P hybrid. a Low-magnification SEM images of FeP/Ni 2 P nanoparticles supported on $\mathrm{Ni}$ foam. Scale bar, $5 \mu \mathrm{m}$. b High-magnification SEM images of FeP/ $\mathrm{Ni}_{2} \mathrm{P}$ nanoparticles supported on Ni foam. Scale bar, $200 \mathrm{~nm}$. c The SAED pattern taken from the FeP/ $/ \mathrm{Ni}_{2} \mathrm{P}$ catalysts. Scale bar, $21 / \mathrm{nm}$. d A typical HRTEM image taken from the FeP/ $\mathrm{Ni}_{2} \mathrm{P}$ catalysts. Scale bar, $2 \mathrm{~nm}$. e The TEM image and corresponding EDX elemental mapping. Scale bar, $100 \mathrm{~nm}$. $\mathbf{f}$ XPS analysis. $\mathbf{g}$ A typical XRD pattern of the samples (we did not show the full intensity of the peaks from $\mathrm{Ni}$ so that the peaks from the catalysts can be better viewed)

electrode relative to $\mathrm{Ni}_{2} \mathrm{P}$ and benchmark $\mathrm{IrO}_{2}$ catalysts. The effect of capacitive current on the catalytic activity, originating from the $\mathrm{Ni}$ ions oxidation, is minimized by calculating the average activity from the forward and backward sweeps of a cyclic voltammetry (CV) curve (Supplementary Fig. 5) ${ }^{30,31}$. Strikingly, the $\mathrm{Fe}-\mathrm{Ni}-\mathrm{P}$ hybrid requires an overpotential of only $154 \mathrm{mV}$ to deliver $10 \mathrm{~mA} \mathrm{~cm}^{-2}$, which is $127 \mathrm{mV}$ less than the state-of-theart $\mathrm{IrO}_{2}$ catalyst $(281 \mathrm{mV})$. At $281 \mathrm{mV}$, our $\mathrm{FeP} / \mathrm{Ni}_{2} \mathrm{P}$ catalyst achieves a current density up to $690 \mathrm{~mA} \mathrm{~cm}^{-2}$, which is 69 -fold higher than the benchmark $\mathrm{IrO}_{2}$, demonstrating a huge improvement of the OER activity. Indeed this overpotential of $154 \mathrm{mV}$ in alkaline conditions is among the lowest for catalyzing OER thus far (Supplementary Table 2), even surpassing the presently most active NiFe $\mathrm{LDH}$ (double layered hydroxide) catalyst $(\sim 200 \mathrm{mV})^{16,32}$. We measured a very small Tafel slope of $22.7 \mathrm{mV} \mathrm{dec}^{-1}$ in the low overpotential ranges ${ }^{33}$ (Fig. 2c, Supplementary Fig. 6), which is much smaller than those of the reference materials $\mathrm{Ni}_{2} \mathrm{P}\left(102.3 \mathrm{mV} \mathrm{dec}{ }^{-1}\right)$ and $\mathrm{IrO}_{2}(71.7 \mathrm{mV}$ $\mathrm{dec}^{-1}$ ), and also smaller than most of the OER catalysts reported (Supplementary Table 2). Specifically, we further compared the OER activity with other available bifunctional catalysts as shown in Fig. $2 \mathrm{~d}$ and e. It is evident that our catalyst requires the lowest overpotential $154 \mathrm{mV}$ to achieve $10 \mathrm{~mA} \mathrm{~cm}^{-2}$, and very large current density $\left(1277 \mathrm{~mA} \mathrm{~cm}^{-2}\right)$ at $300 \mathrm{mV}$ overpotential, indicating the potential to be used for overall water splitting with large current densities at small cell voltage.

To elucidate the origins of this remarkably high OER catalytic activity, we performed electrochemical impedance spectroscopy (EIS) and double-layer capacitance $\left(C_{\mathrm{dl}}\right)$ investigations on this
FeP/Ni ${ }_{2} \mathrm{P}$ electrode. This capacitance $C_{\mathrm{dl}}$ determined by a simple CV method ${ }^{5,29,34-36}$ (Supplementary Fig. 7) is calculated to be $19.3 \mathrm{mF} \mathrm{cm}^{-2}$ for the Fe-Ni-P hybrid electrode (Fig. 2f), very close to that of the $\mathrm{Ni}_{2} \mathrm{P}$ catalyst $\left(14.5 \mathrm{mF} \mathrm{cm}{ }^{-2}\right)$. This manifests that depositing $\mathrm{FeP}$ on the $\mathrm{Ni}_{2} \mathrm{P}$ surface does not result in huge changes in the active surface area, while the electrochemical OER performance of $\mathrm{FeP} / \mathrm{Ni}_{2} \mathrm{P}$ is much better than $\mathrm{Ni}_{2} \mathrm{P}$. For instance, our $\mathrm{FeP} / \mathrm{Ni}_{2} \mathrm{P}$ hybrid achieves $1000 \mathrm{~mA} \mathrm{~cm}{ }^{-2}$ at $293 \mathrm{mV}$, while $\mathrm{Ni}_{2} \mathrm{P}$ can deliver only $32 \mathrm{~mA} \mathrm{~cm}{ }^{-2}$ at this overpotential, making our $\mathrm{FeP} / \mathrm{Ni}_{2} \mathrm{P}$ catalyst $\sim 30$-fold better than the $\mathrm{Ni}_{2} \mathrm{P}$ catalyst, heralding that synergistic effects between $\mathrm{FeP}$ and $\mathrm{Ni}_{2} \mathrm{P}$ in the hybrid is the main contributor to our superior catalytic performance, not just the high active surface area. Meanwhile, the EIS spectra show that this $\mathrm{FeP} / \mathrm{Ni}_{2} \mathrm{P}$ hybrid has a lower charge-transfer resistance at the interface of the catalysts with $\mathrm{Ni}$ foam, leading to faster OER kinetics compared to the $\mathrm{Ni}_{2} \mathrm{P}$ catalyst (Supplementary Fig. 8). Additionally, according to our simulations, both the $\mathrm{FeP}(001) / \mathrm{Ni}_{2} \mathrm{P}$ and $\mathrm{FeP}(010) / \mathrm{Ni}_{2} \mathrm{P}$ have electrons transferred from $\mathrm{Ni}_{2} \mathrm{P}$ to $\mathrm{FeP}$ at neutral with $0.15 \mathrm{C} \mathrm{m}^{-2}$ and $0.097 \mathrm{C} \mathrm{m}^{-2}$, or $0.075 \mathrm{e}^{-}$and $0.051 \mathrm{e}^{-}$per surface $\mathrm{Ni}$, respectively. Since electrons are depleted on $\mathrm{Ni}_{2} \mathrm{P}$, holes are created and the Fermi level on $\mathrm{Ni}_{2} \mathrm{P}$ is shifted downwards, which facilitates the OER process. Especially, the charge transfers in the presence of 2, 3, and 4 layers of $\mathrm{FeP}$ on $\mathrm{Ni}_{2} \mathrm{P}$ were further calculated to understand the effect of different loadings of $\mathrm{FeP}$ on OER activities. The corresponding values are $0.009 \mathrm{e}^{-}, 0.075 \mathrm{e}^{-}$, and $0.078 \mathrm{e}^{-}$per surface $\mathrm{Ni}$, respectively. The result of converging charge transfers in the presence of more $\mathrm{FeP}$ implies that there is no more advantage in charge transfer beyond a certain amount of 

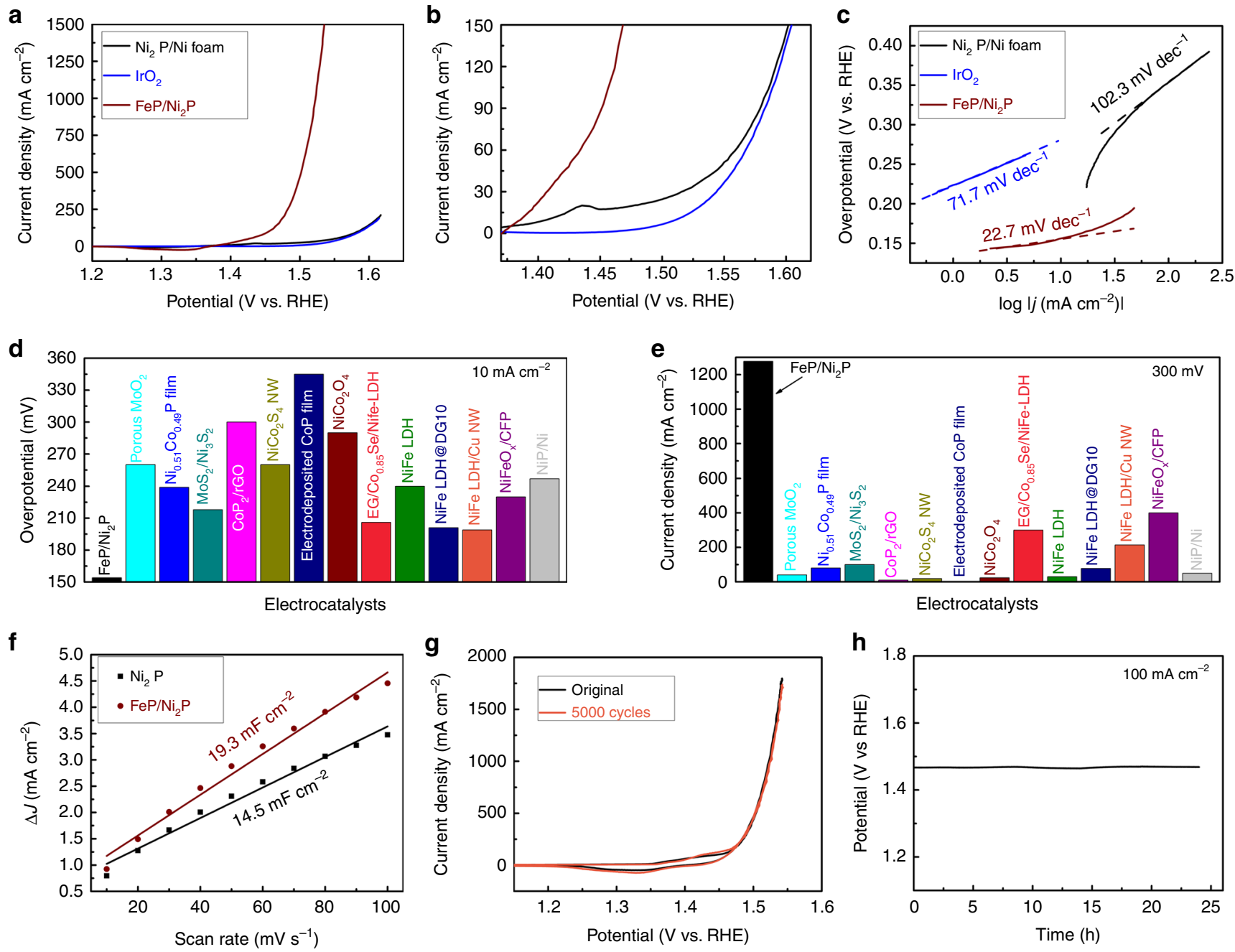

Fig. 2 Electrocatalytic oxygen evolution reaction. a The polarization curves recorded on different catalysts. $\mathbf{b}$ The enlarged region of the curves in $\mathbf{a} . \mathbf{c}$ The corresponding Tafel plots. d Comparison of the overpotentials required at $10 \mathrm{~mA} \mathrm{~cm}{ }^{-2}$ among our catalyst and available reported OER catalysts. e Comparison of the current densities delivered at $300 \mathrm{mV}$ among our catalyst and available reported OER catalysts. $\mathbf{f}$ Double-layer capacitance $\left(C_{\text {dl }}\right)$ measurements of $\mathrm{Ni}_{2} \mathrm{P}$ and $\mathrm{FeP} / \mathrm{Ni}_{2} \mathrm{P}$ catalysts. $\mathbf{g}$ Cyclic voltammetry $(\mathrm{CV})$ curves of $\mathrm{FeP} / \mathrm{Ni}_{2} \mathrm{P}$ before and after the acceleration durability test for 5000 cycles. h Time-dependent potential curve for $\mathrm{FeP} / \mathrm{Ni}_{2} \mathrm{P}$ at $100 \mathrm{~mA} \mathrm{~cm}{ }^{-2}$. Electrolyte: $1 \mathrm{M} \mathrm{KOH}$

FeP is used, which leads to similar activities. Furthermore, the catalytic OER performances were compared by growing additional $\mathrm{Ni}_{2} \mathrm{P}$ particles, $\mathrm{FeP}$ particles with different catalyst loadings on top of Ni foam (Supplementary Figs. 9-11). It is obvious that increasing the loading of $\mathrm{Ni}_{2} \mathrm{P}$ particles has very few effects on improving the OER performances, and an oxidation peak regarding the $\mathrm{Ni}^{\mathrm{II}}$ to $\mathrm{Ni}^{\mathrm{III}}$ becomes stronger with the increase of $\mathrm{Ni}_{2} \mathrm{P}$ loadings (Supplementary Fig. 9). Once FeP particles were grown atop the $\mathrm{Ni}_{2} \mathrm{P} / \mathrm{Ni}$ foam, the performance can be greatly enhanced due to the following reasons: the $\mathrm{Ni}_{2} \mathrm{P} / \mathrm{Ni}$ support has good conductivity and high surface area for growing uniform FeP particles in small size with enhanced OER activity, the oxidation peak of $\mathrm{Ni}^{\mathrm{II}}$ to $\mathrm{Ni}^{\mathrm{iII}}$ can be weakened by $\mathrm{FeP}$ modification (Supplementary Fig. 9-11), and many Fe impurities are possibly provided to improve the catalytic activity of underlying $\mathrm{Ni}_{2} \mathrm{P}$ catalyst by $\mathrm{Fe}$ incorporation ${ }^{37}$. All these information confirms strong synergistic effects between $\mathrm{FeP}$ and $\mathrm{Ni}_{2} \mathrm{P}$ particles. Finally, it is noted that there are a large amount of oxidized species at the surface of original $\mathrm{FeP} / \mathrm{Ni}_{2} \mathrm{P}$ (Supplementary Fig. 3). These surface oxidized species may play a positive role in the OER activity according to recent studies ${ }^{38-40}$. It is possible that they act as a labile ligand to vary the coordination or chelating modes during the redox switching process, and also facilitates the $4 \mathrm{e}$ multiproton-coupled electron transfers step in the OER process. The formation of metal phosphide-metal oxide interface may also be helpful to the efficient carrier transportation from the phosphide core to the oxidized species ${ }^{40}$. Therefore, we attributed the excellent OER activity of our $\mathrm{FeP} / \mathrm{Ni}_{2} \mathrm{P}$ hybrid catalyst to the presence of surface oxidized species, fast electron transport, and synergistic effects between $\mathrm{FeP}$ and $\mathrm{Ni}_{2} \mathrm{P}$.

Electrochemical durability is another key index to evaluate the performance of electrocatalysts. Obviously, after 5000 cycling test, the $\mathrm{CV}$ curve of this $\mathrm{FeP} / \mathrm{Ni}_{2} \mathrm{P}$ hybrid is nearly identical to the original one, suggesting its excellent durability during cycling scans (Fig. 2g). We also probed the long-term electrochemical stability of the catalyst tested at $100 \mathrm{~mA} \mathrm{~cm}^{-2}$, finding that the real-time potential remains nearly constant during a $24 \mathrm{~h}$ continuous operation (Fig. 2h). These results establish the strong durability of $\mathrm{FeP} / \mathrm{Ni}_{2} \mathrm{P}$ catalyst for OER in alkaline electrolyte. Further insights into the chemical compositions for post-OER samples by XPS (Supplementary Fig. 12) and XRD (Supplementary Fig. 13) confirm that a mixture of nickel and iron oxides/ oxyhydroxides evolves at the surface of the $\mathrm{FeP} / \mathrm{Ni}_{2} \mathrm{P}$ hybrid, possibly acting as the real active sites for $\mathrm{OER}^{6}$. This behavior is 
also observed for many metal sulfides ${ }^{41}$, phosphides ${ }^{42}$, or selenides ${ }^{19}$, which are easily oxidized to oxides or hydroxides under the OER process at high anodic potentials.

Hydrogen evolution catalysis. In addition to the excellent OER performance, we found that this $\mathrm{FeP} / \mathrm{Ni}_{2} \mathrm{P}$ hybrid is highly active towards HER in the same electrolyte. It is evident that the bare $\mathrm{Ni}_{2} \mathrm{P}$ is not a good HER catalyst requiring a large overpotential of $150 \mathrm{mV}$ to deliver a current density of $-10 \mathrm{~mA} \mathrm{~cm}^{-2}$ (Fig. 3a, Supplementary Fig. 14). Distinctly, our $\mathrm{FeP} / \mathrm{Ni}_{2} \mathrm{P}$ hybrid obtains $-10 \mathrm{~mA} \mathrm{~cm}^{-2}$ at an extremely low overpotential of $14 \mathrm{mV}$, which is the lowest value among non-noble metal-based HER catalysts (Supplementary Table 3), and indeed is comparable to that of $\mathrm{Pt}$ $(59 \mathrm{mV})$ in alkaline electrolyte. Meanwhile, the Tafel slope of this $\mathrm{FeP} / \mathrm{Ni}_{2} \mathrm{P}$ catalyst is only $24.2 \mathrm{mV} \mathrm{dec}{ }^{-1}$ in the low overpotential ranges (Fig. 3b, Supplementary Fig. 15), which is lower than that

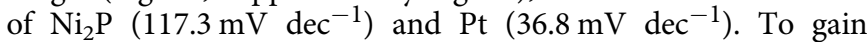
further insight into the outstanding HER activity, the $C_{\mathrm{dl}}$ values (Fig. 3c, Supplementary Fig. 16) were utilized to compare the active surface area, confirming that both high active surface area $\left(907.8 \mathrm{mF} \mathrm{cm}^{-2}\right)$ and small charge-transfer resistance
(Supplementary Fig. 17) contribute greatly to the outstanding HER catalytic activity of this $\mathrm{FeP} / \mathrm{Ni}_{2} \mathrm{P}$ hybrid ${ }^{5,23}$. It is noted that the capacitance is different when the same $\mathrm{FeP} / \mathrm{Ni}_{2} \mathrm{P}$ catalyst was used for HER and OER, which is possibly due to the different origins of active sites for the OER and HER. In particular, we prepared pure $\mathrm{Ni}_{2} \mathrm{P}^{*}$ catalyst on $\mathrm{Ni}$ foam with similar mass loading in the same growth conditions as $\mathrm{FeP} / \mathrm{Ni}_{2} \mathrm{P}$. In this case, we found that $\mathrm{Ni}_{2} \mathrm{P}^{*}$ catalyst still shows catalytic activity inferior to the $\mathrm{FeP} / \mathrm{Ni}_{2} \mathrm{P}$ hybrid, and has a smaller $C_{\mathrm{dl}}$ value (Fig. $3 \mathrm{c}$ ). After normalizing the polarization curves by the active surface area or $C_{\mathrm{dl}}$ difference, the $\mathrm{FeP} / \mathrm{Ni}_{2} \mathrm{P}$ hybrid still exhibits better catalytic HER activity than pure $\mathrm{Ni}_{2} \mathrm{P}^{*}$ catalyst (Supplementary Fig. 18), meaning that $\mathrm{FeP} / \mathrm{Ni}_{2} \mathrm{P}$ has better intrinsic activity than pure $\mathrm{Ni}_{2} \mathrm{P}^{*}$ catalyst. Then the intrinsic catalytic activity was assessed by the turnover frequency (TOF) for each active site quantified by an electrochemical method ${ }^{43}$ (Supplementary Note 1, Supplementary Fig. 19). From this method, the number of active catalytic sites for the $\mathrm{FeP} / \mathrm{Ni}_{2} \mathrm{P}$ hybrid is around 2.5 times that of the $\mathrm{Ni}_{2} \mathrm{P}^{*}$ catalyst, and accordingly the TOF of the $\mathrm{FeP} / \mathrm{Ni}_{2} \mathrm{P}$ hybrid is calculated to be $0.163 \mathrm{~s}^{-1}$ at $100 \mathrm{mV}$ overpotential, which is much higher than that of pure $\mathrm{Ni}_{2} \mathrm{P}^{*}$ catalyst
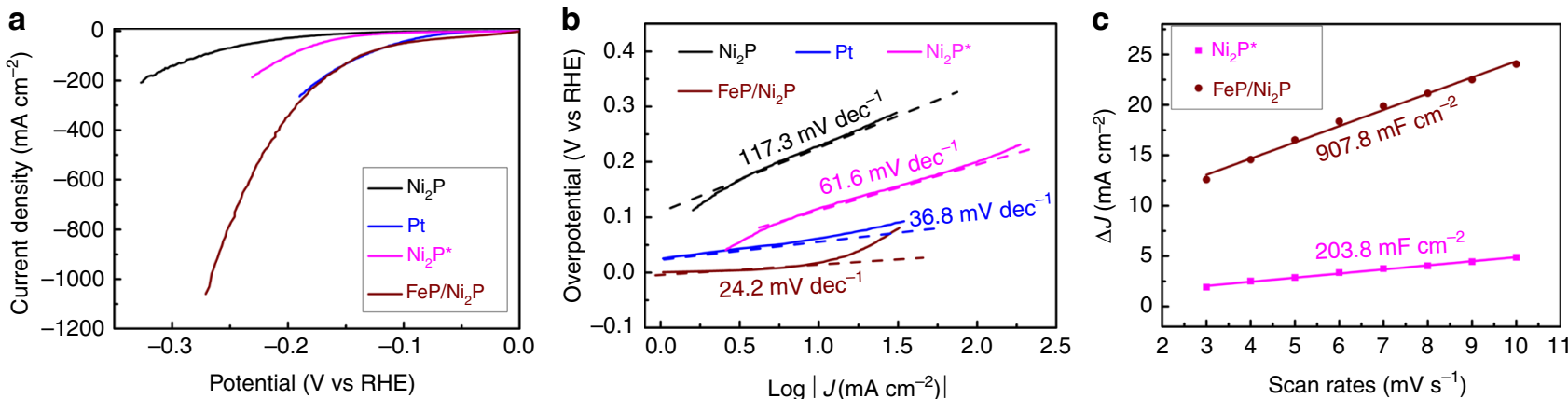

d

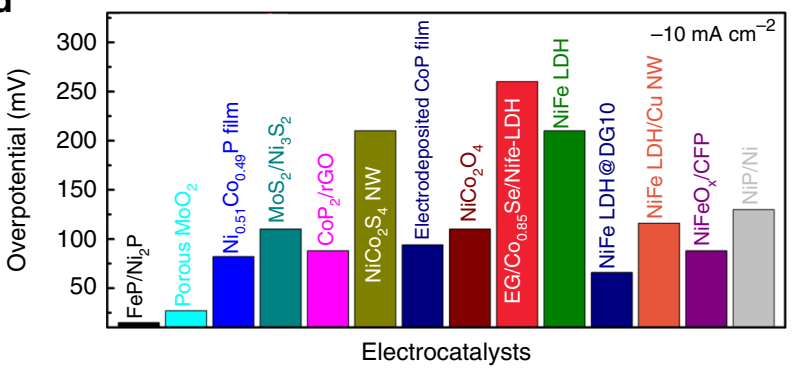

f

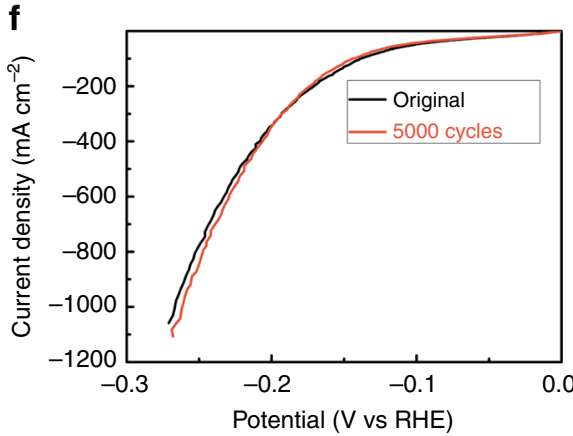

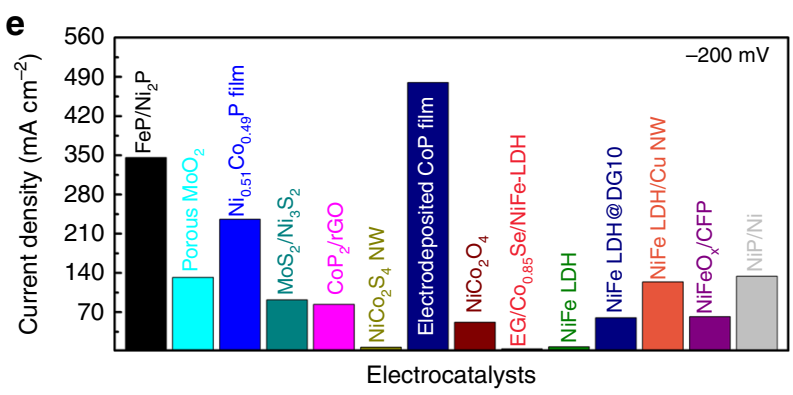

g

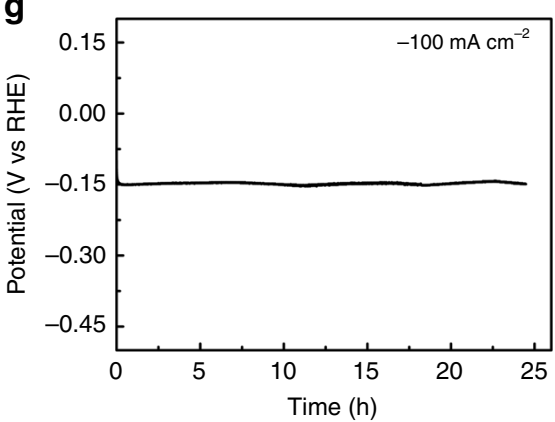

h

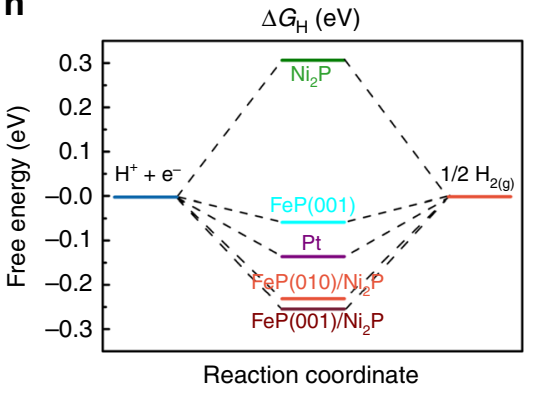

Fig. 3 Electrocatalytic hydrogen evolution reaction. a The HER polarization curves of different catalysts. b The relevant Tafel plots. c Double-layer capacitance measurements for determining electrochemically active surface areas of $\mathrm{Ni}_{2} \mathrm{P}$ and FeP/Ni $2 \mathrm{P}$ electrodes. $\mathbf{d}$ Comparison of the overpotentials required at $10 \mathrm{~mA} \mathrm{~cm}^{-2}$ among our catalyst and available reported HER catalysts. e Comparison of the current densities delivered at $-200 \mathrm{mV}$ among our catalyst and available reported HER catalysts. f Polarization curves before and after 5000 cycling test. $\mathbf{g}$ The chronopotentiometric curve of the $\mathrm{FeP} / \mathrm{Ni}_{2} \mathrm{P}$ electrode tested at a constant current density of $-100 \mathrm{~mA} \mathrm{~cm}{ }^{-2}$ for $24 \mathrm{~h}$. $\mathbf{h}$ Free energy diagram for $\Delta \mathrm{G}_{\mathrm{H}}$, the hydrogen adsorption free energy at $\mathrm{pH}=14$ on $\mathrm{FeP} / \mathrm{Ni}_{2} \mathrm{P}$ catalyst in comparison with $\mathrm{Ni}_{2} \mathrm{P}$ and benchmark Pt catalysts. Electrolyte: $1 \mathrm{M} \mathrm{KOH}$ 

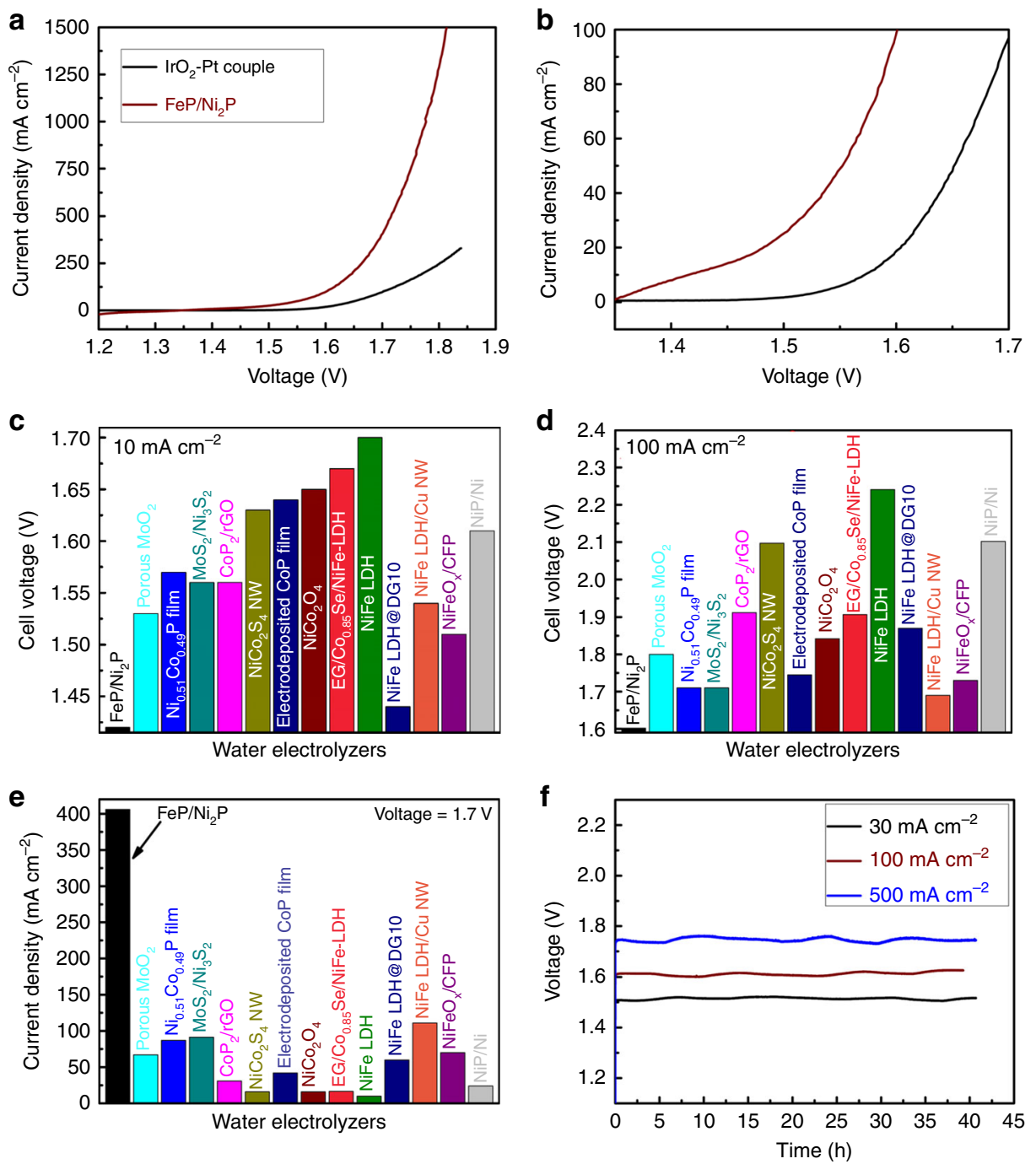

Fig. 4 Overall-water-splitting activity of the $\mathrm{FeP} / \mathrm{Ni}_{2} \mathrm{P}$ catalyst. a The polarization curve of $\mathrm{FeP} / \mathrm{Ni}_{2} \mathrm{P}$ and $/ \mathrm{IO}_{2}-\mathrm{Pt}$ coupled catalysts in a two-electrode configuration. b Enlarged version at low current density region of a. c Comparison of the cell voltages to achieve $10 \mathrm{~mA} \mathrm{~cm}{ }^{-2}$ among different water alkaline electrolyzers. $\mathbf{d}$ Comparison of the cell voltages to achieve $100 \mathrm{~mA} \mathrm{~cm}{ }^{-2}$ among different water alkaline electrolyzers. e Comparison of the current densities at $1.7 \mathrm{~V}$ for this $\mathrm{FeP} / \mathrm{Ni}_{2} \mathrm{P}$ catalyst with available non-noble bifunctional catalysts. $\mathbf{f}$ Catalytic stability of the FeP/Ni $2 \mathrm{P}$ catalysts at 30,100 , and $500 \mathrm{~mA} \mathrm{~cm}^{-2}$ for around $40 \mathrm{~h}$. Electrolyte: $1 \mathrm{M} \mathrm{KOH}$

$\left(0.006 \mathrm{~s}^{-1}\right)$ at the same overpotential, suggesting that the addition of $\mathrm{FeP}$ particles on $\mathrm{Ni}_{2} \mathrm{P}$ surface contributes more to the improvement of the HER activities of this $\mathrm{FeP} / \mathrm{Ni}_{2} \mathrm{P}$ hybrid. This is further supported by measuring the catalytic activities of additional $\mathrm{Ni}_{2} \mathrm{P}$ or $\mathrm{FeP}$ particles with different loadings grown on $\mathrm{Ni}_{2} \mathrm{P} / \mathrm{Ni}$ support (Supplementary Fig. 9-11). More interestingly, this $\mathrm{FeP} / \mathrm{Ni}_{2} \mathrm{P}$ hybrid still shows outstanding HER activity compared to other available bifunctional catalysts (Fig. $3 \mathrm{~d}$ and e). To evaluate its stability during electrochemical HER, a long-term cycling test (Fig. 3f) and continuous operation for $24 \mathrm{~h}$ of hydrogen release at $-100 \mathrm{~mA} \mathrm{~cm}^{-2}$ (Fig. $3 \mathrm{~g}$ ) were performed in $1 \mathrm{M} \mathrm{KOH}$, demonstrating its good stability.

In order to figure out the factors contributing to the superior HER activity, we performed density functional theory (DFT) calculations on this catalyst. According to Fig. 1d, (021) and (010) lattice planes are observed on $\mathrm{Ni}_{2} \mathrm{P}$ nanoparticles. Since (021) and (010) of $\mathrm{Ni}_{2} \mathrm{P}$ have a simple common perpendicular direction (100), we chose this plane to model $\mathrm{Ni}_{2} \mathrm{P}$ (Supplementary Fig. 20). On the other hand, the two directions, (220) and (103) on FeP, do not share a common simple perpendicular direction, hence we chose two different directions, (001) and (010), to model FeP.
Since the overall system involved two materials, the interactions between $\mathrm{FeP}$ and $\mathrm{Ni}_{2} \mathrm{P}$ were modeled by placing $\mathrm{FeP}$ on top of $\mathrm{Ni}_{2} \mathrm{P}$, which is reasonable since an $\mathrm{Ni}$ foam was used as the material on which $\mathrm{Ni}_{2} \mathrm{P}$ and $\mathrm{FeP}$ were grown. The corresponding lattice distances were chosen to minimize the percent changes in both $\mathrm{Ni}_{2} \mathrm{P}$ and $\mathrm{FeP}$. The hydrogen adsorption energy, $\Delta G_{\mathrm{H}}$, was calculated in the same way as in our previous study ${ }^{5}$ and is shown in Supplementary Table 4. As shown in Fig. 3h, Supplementary Fig. 20 and Supplementary Table 4, pure $\mathrm{Ni}_{2} \mathrm{P}$ (001) leads to a relatively strong exothermic $\Delta G_{\mathrm{H}}(0.306 \mathrm{eV})$, indicating that it is not the most active center for the hydrogen evolution electrocatalysis, which we confirmed experimentally (Fig. 3a, b, Supplementary Fig. 18). However, this hydrogen adsorption energy $\left|\Delta G_{\mathrm{H}}\right|$ is reduced significantly to 0.255 and $0.230 \mathrm{eV}$ for a very thin $\mathrm{FeP}(100)$ or $\mathrm{FeP}(010)$ crystal ( $~ 3$ layers), respectively, hybridized atop with $\mathrm{Ni}_{2} \mathrm{P}$. It is worth pointing out that we confine our calculation a thin layer of FeP crystal, ignoring the particulate size $(5-30 \mathrm{~nm})$, so we hypothesized that the as-synthesized $\mathrm{FeP}$ nanoparticles along with $\mathrm{Ni}_{2} \mathrm{P}$ preferentially expose the most active facets as those of bulk FeP (001) crystal, which results in further reduction of $\left|\Delta G_{\mathrm{H}}\right|$ to only $0.06 \mathrm{eV}$, 
contributing to the high activity not seen in typical FeP crystals. This conclusion is also supported by the above experiments regarding the TOF calculation. Thus, both the experiment and theory support that this hybrid catalyst is an efficient HER electrocatalyst.

Overall water splitting. Given the outstanding OER and HER activities in $1 \mathrm{M} \mathrm{KOH}$ electrolyte, we further utilized this $\mathrm{FeP} /$ $\mathrm{Ni}_{2} \mathrm{P}$ hybrid as both anode and cathode in a two-electrode configuration for overall water splitting in the same electrolyte. Remarkably, the cell voltage to afford a current density of $10 \mathrm{~mA}$ $\mathrm{cm}^{-2}$ is as low as $1.42 \mathrm{~V}$ with a relatively low Tafel slope of 69.5 $\mathrm{mV} \operatorname{dec}^{-1}$ (Fig. 4a, b, Supplementary Figs. 21 and 22), substantially lower than that of the coupled benchmark $\mathrm{IrO}_{2}-\mathrm{Pt}$ catalysts $(1.57 \mathrm{~V})$, and superior to most previously reported bifunctional electrocatalysts, which generally need cell voltages higher than $1.50 \mathrm{~V}$ to deliver the same current density (Fig. 4c, Supplementary Table 5). This cell voltage also manifests that the electrical-to-fuel efficiency of water-splitting electrolyzers at $10 \mathrm{~mA} \mathrm{~cm}^{-2}$ is dramatically elevated to $86.6 \%$ using only this material, making it of great potential for scale-up water electrolysis with high efficiency and low cost. Even though the best bifunctional NiFe LDH catalyst reported recently can deliver 20 $\mathrm{mA} \mathrm{cm}-2$ at a cell voltage of $1.50 \mathrm{~V}$, which is close to our $\mathrm{FeP} /$ $\mathrm{Ni}_{2} \mathrm{P}$ catalyst $(1.48 \mathrm{~V})$, but a much larger cell voltage of $1.70 \mathrm{~V}$ is needed to achieve only $60 \mathrm{~mA} \mathrm{~cm}^{-2}$, meaning low energy conversion efficiency at high current density ${ }^{16}$. Nearly all the bifunctional electrocatalysts require larger than $1.69 \mathrm{~V}$ to reach $100 \mathrm{~mA} \mathrm{~cm}^{-2}$ for the overall water splitting (Fig. 4d). Even at 1.7 $\mathrm{V}$ cell voltage, most of the electrolyzers can only deliver current densities below $110 \mathrm{~mA} \mathrm{~cm}^{-2}$ (Fig. 4e). In contrast, our FeP/Ni $\mathrm{Ni}_{2} \mathrm{P}$ catalyst can readily drive water electrolysis at high current densities of 100,500 , and $1000 \mathrm{~mA} \mathrm{~cm}^{-2}$ at very low cell voltages of $1.60,1.72$, and $1.78 \mathrm{~V}$, respectively, showing that our catalyst performs outstandingly over the full range of current density. We further tested the long-term stability of our $\mathrm{FeP} / \mathrm{Ni}_{2} \mathrm{P}$ electrode at 30 and $100 \mathrm{~mA} \mathrm{~cm}^{-2}$ for $36 \mathrm{~h}$, showing no detectable voltage decay (Fig. 4f). Moreover, we further examined extremely highcurrent operation of the electrolyzer at $1.72 \mathrm{~V}$ for overall water splitting at $500 \mathrm{~mA} \mathrm{~cm}^{-2}$, which is a big step toward real industrial applications ${ }^{6,22}$. In comparison, commercial alkaline water electrolysis ${ }^{10,15}$ requires $1.8-2.4 \mathrm{~V}$ to generate $200-400 \mathrm{~mA}$ $\mathrm{cm}^{-2}$, while no previous bifunctional catalysts show catalytic activities superior to the commercial ones with good durability at high current density above $200 \mathrm{~mA} \mathrm{~cm}^{-2}$. In contrast, our alkaline electrolyzer only requires $1.72 \mathrm{~V}$ to afford $500 \mathrm{~mA} \mathrm{~cm}^{-2}$ while also exhibiting excellent stability for more than $40 \mathrm{~h}$ confirmed by steady chronopotentiometric testing (Fig. 4f). Especially, using the gas chromatography-based technique ${ }^{5}$, we found that $\mathrm{H}_{2}$ and $\mathrm{O}_{2}$ are the only gas products during water electrolysis, and the molar ratio between $\mathrm{H}_{2}$ and $\mathrm{O}_{2}$ is close to 2:1 (Supplementary Fig. 23), suggesting that nearly all the electrons are actively involved in the catalytic reaction. This demonstrates outstanding overall-water-splitting activity of our hybrid catalyst, making it an excellent condition for industrial use.

\section{Discussion}

In summary, we developed an $\mathrm{FeP} / \mathrm{Ni}_{2} \mathrm{P}$ hybrid catalyst supported on $3 \mathrm{D} \mathrm{Ni}$ foam that proves to be an outstanding bifunctional catalyst for overall water splitting, exhibiting both extremely high OER and HER activities in the same alkaline electrolyte. Indeed, it requires a very low cell voltage of $1.42 \mathrm{~V}$ to afford $10 \mathrm{~mA} \mathrm{~cm} \mathrm{~cm}^{-2}$ in alkaline water electrolyzers, while at the commercially practical current density of $500 \mathrm{~mA} \mathrm{~cm}^{-2}$, it demands only a voltage of
$1.72 \mathrm{~V}$ lower than those for any reported bifunctional catalysts, and maintains its excellent catalytic activity for more than $40 \mathrm{~h}$ at a current density of $500 \mathrm{~mA} \mathrm{~cm}{ }^{-2}$, paving the way for promising large-scale hydrogen generation.

\section{Methods}

Chemicals. Red phosphorous powder (Sigma-Aldrich, $\geq 97 \%$, CAS No. 7723-14-0), Iron(III) nitrate nonahydrate [Sigma-Aldrich, $\mathrm{Fe}\left(\mathrm{NO}_{3}\right)_{3} \cdot 9 \mathrm{H}_{2} \mathrm{O}, \geq 99.95 \%$, CAS No. 7782-61-8], Pt wire (CH Instruments, Inc.), Nafion 117 solution (5\%; SigmaAldrich), iridium oxide powder (Alfa Aesar, $\mathrm{IrO}_{2}, 99 \%$ ), potassium hydroxide (Alfa Aesar, $\mathrm{KOH}, 50 \% \mathrm{wt} / \mathrm{vol}$ ), and $\mathrm{Ni}$ foam (areal density $320 \mathrm{~g} \mathrm{~cm}^{-2}$ ) $\left(\mathrm{ref}^{2}\right.$ ) were used without further purification.

Material synthesis. These metal phosphides $\left(\mathrm{Ni}_{2} \mathrm{P}\right.$ and $\left.\mathrm{FeP}\right)$ were grown by chemical vapor deposition in a tube furnace, in which $\mathrm{Ni}$ foam, $\mathrm{Fe}\left(\mathrm{NO}_{3}\right)_{3}$, and phosphorus were utilized as the $\mathrm{Ni}, \mathrm{Fe}$, and $\mathrm{P}$ sources, respectively. Namely, we first immersed a commercially hydrophobic $\mathrm{Ni}$ foam into an aqueous $\mathrm{Fe}\left(\mathrm{NO}_{3}\right)_{3}$ solution $(0.37 \mathrm{M})$, which was then converted to mainly $\mathrm{Ni}_{2} \mathrm{P}$ and a very small fraction of $\mathrm{FeP}$ at $450^{\circ} \mathrm{C}$ in $\mathrm{Ar}$ atmosphere, with phosphorus powder supplied upstream. After that, the samples were naturally cooled down under Ar gas protection, which became hydrophilic after first phosphidation. In the following, a second-time phosphidation was performed after the samples were immersed into the $\mathrm{Fe}\left(\mathrm{NO}_{3}\right)_{3}$ solution again. The catalyst loading is around $8 \mathrm{mg} \mathrm{cm}^{-2}$ for the $\mathrm{FeP} / \mathrm{Ni}_{2} \mathrm{P}$ catalyst. For comparison, the as-prepared $\mathrm{Ni}_{2} \mathrm{P}$ samples were obtained in the same growth conditions without the addition of $\mathrm{Fe}\left(\mathrm{NO}_{3}\right)_{3}$, and the $\mathrm{Ni}_{2} \mathrm{P}^{*}$ samples were grown in the same experimental conditions by using $\mathrm{Ni}\left(\mathrm{NO}_{3}\right)_{2}(0.37 \mathrm{M})$ instead of $\mathrm{Fe}\left(\mathrm{NO}_{3}\right)_{3}$. Three different concentrations of $\mathrm{Fe}\left(\mathrm{NO}_{3}\right)_{3}(0.25,0.37$, and $0.50 \mathrm{M})$ and $\mathrm{Ni}\left(\mathrm{NO}_{3}\right)_{2}$ $(0.17,0.37$, and $0.50 \mathrm{M})$ precursors were prepared to grow different catalyst loadings of $\mathrm{FeP}\left(6.0,8.0\right.$, and $\left.12.5 \mathrm{mg} \mathrm{cm}^{-2}\right)$ or $\mathrm{Ni}_{2} \mathrm{P}$ particles $(3.0,7.5$, and $10.5 \mathrm{mg} \mathrm{cm}^{-2}$ ) on the surface, respectively, so as to optimize the experimental conditions and relevant catalytic activities for the HER and OER. The optimal loading of $\mathrm{FeP} / \mathrm{Ni}_{2} \mathrm{P}$ hybrid catalysts was found to be around $8 \mathrm{mg} \mathrm{cm}-2$ on $\mathrm{Ni}$ foam.

Electrochemical characterization. The electrochemical tests were performed via a typical three-electrode configuration in $100 \mathrm{ml} 1 \mathrm{M} \mathrm{KOH}$ electrolyte ${ }^{6,29}$. The polarization curves for the HER were recorded by linear sweep voltammetry with a scan rate of $1.0 \mathrm{mV} \mathrm{s}^{-1}$. For the OER and overall water splitting, in order to minimize the effect of capacitive current originating from the $\mathrm{Ni}$ ions oxidation on the catalytic performance, $\mathrm{CV}$ curves with the forward and backward sweeps with a very small scan rate of $1 \mathrm{mV} \mathrm{s}^{-1}$ were utilized to calculate the average activity. A carbon paper was used as the counter electrode for both the HER and OER tests. The scan rate for the cycling tests was set to $50 \mathrm{mV} \mathrm{s}^{-1}$. All the potentials shown here were converted to RHE.

Computational methods. GGA level of DFT was employed to calculate the relative energies of relevant structures in this study. More specifically, $\mathrm{PBE}^{44,45}$ functional with the D3 ${ }^{46}$ correction was used for both geometry optimizations and the single point free energies. Geometry optimizations were performed in VASP ${ }^{47,48}$ with projected augmented wave (PAW) $)^{49,50}$ and VASPsol ${ }^{51}$ solvation. The kinetic energy cutoff was $300 \mathrm{eV}$ for geometry optimization, and 13 Hartree $(354 \mathrm{eV})$ for single point energy. The single point free energies were calculated in $\mathrm{jDFTx}^{52-56}$ with CANDLE ${ }^{57}$ implicit solvation and GBRV uspp pseudopotentials. The final free energy $G$ was calculated as $G=F-n_{\mathrm{e}} U+\mathrm{ZPE}+H_{\mathrm{vib}}-T S_{\mathrm{vib}}$, where $F$ is the energy of the solvated Kohn-Sham DFT electronic system, $n_{\mathrm{e}}$ is the number of electrons, and $U$ is the chemical potential for the electrons. Also, in order to understand the charge transfer process between $\mathrm{Ni}_{2} \mathrm{P}$ and $\mathrm{FeP}$, we calculated the Mulliken charges of the hybrid $\mathrm{Fe} / \mathrm{Ni}_{2} \mathrm{P}$ structure and summed up the charges for each compound. Since Mulliken charges can only be rigorously defined using localized basis functions, we performed this set of DFT calculations on the same structures used in the HER part of the study using Gaussian basis functions in CRYSTAL14 with PBE and the same k-point grid.

Data availability. The data that support the findings of this work are available from the corresponding author upon reasonable request.

Received: 27 November 2017 Accepted: 17 May 2018 Published online: 29 June 2018

\section{References}

1. Zou, X. X. \& Zhang, Y. Noble metal-free hydrogen evolution catalysts for water splitting. Chem. Soc. Rev. 44, 5148-5180 (2015).

2. Luo, J. S. et al. Water photolysis at $12.3 \%$ efficiency via perovskite photovoltaics and Earth-abundant catalysts. Science 345, 1593-1596 (2014). 
3. Wang, X. G., Kolen'ko, Y. V., Bao, X. Q., Kovnir, K. \& Liu, L. F. One-step synthesis of self-supported nickel phosphide nanosheet array cathodes for efficient electrocatalytic hydrogen generation. Angew. Chem. Int. Ed. 54, 8188-8192 (2015).

4. Faber, M. S. \& Jin, S. Earth-abundant inorganic electrocatalysts and their nanostructures for energy conversion applications. Energy Environ. Sci. 7 , 3519-3542 (2014).

5. Zhou, H. Q. et al. Efficient hydrogen evolution by ternary molybdenum sulfoselenide particles on self-standing porous nickel diselenide foam. Nat. Commun. 7, 12765 (2016).

6. Zhou, H. Q. et al. Highly active catalyst derived from a 3D foam of $\mathrm{Fe}\left(\mathrm{PO}_{3}\right)_{2} / \mathrm{Ni}_{2} \mathrm{P}$ for extremely efficient water oxidation. Proc. Natl. Acad. Sci. USA 114, 5607-5611 (2017).

7. Ng, J. W. D. et al. Gold-supported cerium-doped $\mathrm{NiO}_{\mathrm{x}}$ catalysts for water oxidation. Nat. Energy 1, 16053 (2016).

8. Cheng, N. C. et al. Platinum single-atom and cluster catalysis of the hydrogen evolution reaction. Nat. Commun. 7, 13638 (2016).

9. Leng, Y. et al. Solid-state water electrolysis with an alkaline membrane. J. Am. Chem. Soc. 134, 9054-9057 (2012).

10. Zeng, K. \& Zhang, D. K. Recent progress in alkaline water electrolysis for hydrogen production and applications. Prog. Energy. Combust. Sci. 36, 307-326 (2010).

11. Carmo, M., Fritz, D. L., Merge, J. \& Stolten, D. A comprehensive review on PEM water electrolysis. Int. J. Hydrog. Energy 38, 4901-4934 (2013).

12. Sun, Y., Delucchi, M. \& Ogden, J. The impact of widespread deployment of fuel cell vehicles on platinum demand and price. Int. J. Hydrog. Energy 36, 11116-11127 (2011).

13. Jin, Y. S. et al. Porous $\mathrm{MoO}_{2}$ nanosheets as non-noble bifunctional electrocatalysts for overall water splitting. Adv. Mater. 28, 3785-3790 (2016).

14. Gao, X. H. et al. Hierarchical $\mathrm{NiCo}_{2} \mathrm{O}_{4}$ hollow microcuboids as bifunctional electrocatalysts for overall water splitting. Angew. Chem. Int. Ed. 55, 6290-6294 (2016).

15. Wang, H. T. et al. Bifunctional non-noble metal oxide nanoparticle electrocatalysts through lithium-induced conversion for overall water splitting. Nat. Commun. 6, 7261 (2015).

16. Jia, Y. et al. A heterostructure coupling of exfoliated Ni-Fe hydroxide nanosheet and defective graphene as a bifunctional electrocatalyst for overall water splitting. Adv. Mater. 29, 1700017 (2017).

17. Zhang, J. et al. Interface engineering of $\mathrm{MoS}_{2} / \mathrm{Ni}_{3} \mathrm{~S}_{2}$ heterostructures for highly enhanced electrochemical overall-water-splitting activity. Angew. Chem. Int. Ed. 55, 6701-6706 (2016).

18. Sivanantham, A., Ganesan, P. \& Shanmugam, S. Hierarchical $\mathrm{NiCo}_{2} \mathrm{~S}_{4}$ nanowire arrays supported on $\mathrm{Ni}$ foam: an efficient and durable bifunctional electrocatalyst for oxygen and hydrogen evolution reactions. Adv. Funct. Mater. 26, 4661-4672 (2016).

19. Tang, C., Cheng, N. Y., Pu, Z. H., Xing, W. \& Sun, X. P. NiSe nanowire film supported on nickel foam: an efficient and stable 3D bifunctional electrode for full water splitting. Angew. Chem. Int. Ed. 54, 9351-9355 (2015).

20. Wang, J. M., Yang, W. R. \& Liu, J. Q. $\mathrm{CoP}_{2}$ nanoparticles on reduced graphene oxide sheets as a super-efficient bifunctional electrocatalyst for full water splitting. J. Mater. Chem. A 4, 4686-4690 (2016).

21. Ledendecker, $M$. et al. The synthesis of nanostructured $\mathrm{Ni}_{5} \mathrm{P}_{4}$ films and their use as a non-noble bifunctional electrocatalyst for full water splitting. Angew. Chem. Int. Ed. 54, 12361-12365 (2015).

22. Smith, R. D. L. et al. Photochemical route for accessing amorphous metal oxide materials for water oxidation catalysis. Science 340, 60-63 (2013).

23. Cabán-Acevedo, M. et al. Efficient hydrogen evolution catalysis using ternary pyrite-type cobalt phosphosulphide. Nat. Mater. 14, 1245-1251 (2015).

24. Yang, Y., Fei, H. L., Ruan, G. D. \& Tour, J. M. Porous cobalt-based thin film as a bifunctional catalyst for hydrogen generation and oxygen generation. $A d v$. Mater. 27, 3175-3180 (2015).

25. Zhu, Y. P., Liu, Y. P., Ren, T. Z. \& Yuan, Z. Y. Self-supported cobalt phosphide mesoporous nanorod arrays: a flexible and bifunctional electrode for highly active electrocatalytic water reduction and oxidation. Adv. Funct. Mater. 25, 7337-7347 (2015).

26. Xu, J. Y., Xiong, D. H., Amorim, I. \& Liu, L. F. Template-free synthesis of hollow iron phosphide-phosphate composite nanotubes for use as active and stable oxygen evolution electrocatalysts. ACS Appl. Nano Mater. 1, 617-624 (2018).

27. Tian, J. Q. et al. FeP nanoparticles film grown on carbon cloth: an ultrahighly active $3 \mathrm{D}$ hydrogen evolution cathode in both acidic and neutral solutions. ACS Appl. Mater. Interfaces 6, 20579-20584 (2014).

28. Yan, Y. et al. A flexible electrode based on iron phosphide nanotubes for overall water splitting. Chem. Eur. J. 21, 18062-18067 (2015).

29. Yu, F. et al. Three-dimensional nanoporous ion nitride film as an efficient electrocatalyst for water oxidation. ACS Catal. 7, 2052-2057 (2017).
30. Stevens, M. B. et al. Measurement techniques for the study of thin film heterogeneous water oxidation electrocatalysts. Chem. Mater. 29, 120-140 (2017).

31. Liang, $\mathrm{H}$. W. et al. Molecular metal- $\mathrm{N}_{\mathrm{x}}$ centres in porous carbon for electrocatalytic hydrogen evolution. Nat. Commun. 6, 7992 (2015).

32. $\mathrm{Li}, \mathrm{Z}$. H. et al. Fast electrosynthesis of Fe-containing layered double hydroxide arrays toward highly efficient electrocatalytic oxidation reactions. Chem. Sci. 6 6624-6631 (2015)

33. Shinagawa, T., Garcia-Esparza, Al. T. \& Takanabe, K. Insight on Tafel slopes from a microkinetic analysis of aqueous electrocatalysis for energy conversion. Sci. Rep. 5, 13801 (2015).

34. Zhou, H. Q. et al. Highly efficient hydrogen evolution from edge-oriented $\mathrm{WS}_{2}$ (1-x) $\mathrm{Se}_{2 \mathrm{x}}$ particles on three-dimensional porous $\mathrm{NiSe}_{2}$ foam. Nano Lett. 16, 7604-7609 (2016).

35. Kong, D. S., Wang, H. T., Lu, Z. Y. \& Cui, Y. CoSe $e_{2}$ nanoparticles grown on carbon fiber paper: an efficient and stable electrocatalyst for hydrogen evolution reaction. J. Am. Chem. Soc. 136, 4897-4900 (2014).

36. Mishra, I. K. et al. Highly efficient hydrogen evolution by self-standing nickel phosphide-based hybrid nanosheet arrays electrocatalyst. Mater. Today Phys. 4, 1-6 (2018).

37. Trotochaud, L., Young, S. L., Ranney, J. K. \& Boettcher, S. W. Nickel-iron oxyhydroxide oxygen-evolution electrocatalysts: the role of intentional and incidental iron incorporation. J. Am. Chem. Soc. 136, 6744-6753 (2014).

38. Ahn, H. S. \& Tilley, T. D. Electrocatalytic water oxidation at neutral $\mathrm{pH}$ by a nanostructured $\mathrm{Co}\left(\mathrm{PO}_{3}\right)_{2}$ anode. Adv. Funct. Mater. 23, 227-233 (2013).

39. Chang, J. F. et al. Surface oxidized cobalt-phosphide nanorods as an advanced oxygen evolution catalyst in alkaline solution. ACS Catal. 5, 6874-6878 (2015).

40. Anirban, D. \& Pradhan, N. Developments of metal phosphides as efficient OER precatalysts. J. Phys. Chem. Lett. 8, 144-152 (2017).

41. You, B. \& Sun, Y. J. Hierarchically porous nickel sulfide multifunctional superstructures. Adv. Energy Mater. 6, 1502333 (2016).

42. Stern, L. A., Feng, L. G., Song, F. \& Hu, X. L. $\mathrm{Ni}_{2} \mathrm{P}$ as a Janus catalyst for water splitting: the oxygen evolution activity of $\mathrm{Ni}_{2} \mathrm{P}$ nanoparticles. Energy Environ. Sci. 8, 2347-2351 (2015).

43. Merki, D., Fierro, S., Vrubel, H. \& Hu, X. L. Amorphous molybdenum sulfide films as catalysts for electrochemical hydrogen production in water. Chem. Sci. 2, 1262-1267 (2011).

44. Perdew, J. P., Burke, K. \& Ernzerhof, M. Generalized gradient approximation made simple. Phys. Rev. Lett. 77, 3865 (1996).

45. Perdew, J. P., Burke, K. \& Ernzerhof, M. K+ emission in symmetric heavy ion reactions at subthreshold energies. Phys. Rev. Lett. 78, 1396 (1997).

46. Grimme, S., Antony, J., Ehrlich, S. \& Krieg, S. A consistent and accurate ab initio parametrization of density functional dispersion correction (DFT-D) for the 94 elements H-Pu. J. Chem. Phys. 132, 154104 (2010).

47. Kresse, G. \& Hafner, J. Ab initio molecular dynamics for liquid metals. Phys. Rev. B Condens. Matter Mater. Phys. 47, 558(R) (1993).

48. Kresse, G. \& Furthmuller, J. Efficient iterative schemes for ab initio totalenergy calculations using a plane-wave basis set. Phys. Rev. B Condens. Matter Matter. Phys. 54, 11169 (1996).

49. Blochl, P. E. Projector augmented-wave method. Phys. Rev. B Condens. Matter Mater. Phys. 50, 17953 (1994).

50. Kresse, G. \& Joubert, D. From ultrasoft pseudopotentials to the projector augmented-wave method. Phys. Rev. B Condens. Matter Mater. Phys. 59, 1758 (1999).

51. Mathew, K., Sundararaman, R., Letchworth-Weaver, K., Arias, T. A. \& Hennig, R. G. Implicit solvation model for density-functional study of nanocrystal surfaces and reaction pathways. J. Chem. Phys. 140, 084106 (2014).

52. Ismail-Beigi, S. \& Arias, T. A. New algebraic formulation of density functional calculation. Comput. Phys. Commun. 128, 1-45 (2000).

53. Rozzi, C. A., Varsano, D., Marini, A., Gross, E. K. U. \& Rubio, A. Exact Coulomb cutoff technique for supercell calculations. Phys. Rev. B 73, 205119 (2006).

54. Petrosyan, S. A., Rigos, A. A. \& Arias, T. A. Joint density-functional theory: ab initio study of $\mathrm{Cr}_{2} \mathrm{O}_{3}$ surface chemistry in solution. J. Phys. Chem. B 109, 15436-15444 (2005).

55. Arias, T. A., Payne, M. C. \& Joannopoulos, J. D. Ab initio molecular dynamics: analytically continued energy functionals and insights into iterative solutions. Phys. Rev. Lett. 69, 1077 (1992).

56. Freysoldt, C., Boeck, S. \& Neugebauer, J. Direct minimization technique for metals in density functional theory. Phys. Rev. B 79, 241103(R) (2009).

57. Sundararaman, R. \& Goddard, W. A. The charge-asymmetric nonlocally determined local-electric (CANDLE) solvation model. J. Chem. Phys. 142, 064107 (2015). 


\section{Acknowledgements}

This project has been partially supported by the US Department of Energy under a grant DE-SC0010831. J.S. and S.C. also express their acknowledgements to the support from $\mathrm{TcSUH}$ as the TcSUH Robert A. Welch Professorships in High Temperature Superconducting (HTSg) and Chemical Materials (E-0001). W.A.G. and Y.H. acknowledge support from NSF (CBET 1512759). The calculations were performed on PEREGRINE (NREL), XSEDE (NSF ACI-1053575), and NERSC (DOE DE-AC02-05CH11231). J.B. thanks the support by the Robert A. Welch Foundation (E-1728). H.Z. acknowledge the supports from Hundred Youth Talents Program of Hunan Province and the'XiaoXiang Scholar' Talents Foundation of Hunan Normal University.

\section{Author contributions}

Z.R. led the project. F.Y. and H.Z. designed and performed the majority of the experiments and obtained most of the results including material synthesis, characterization, and electrochemical tests. Y.H. and W.A.G. carried out the DFT calculations. J.S. took the TEM images and analyzed the data. F.Q. and J.B. helped to test the gas chromatography. S.C. devoted to the electrochemical data analysis. F.Y., H.Z., S.C., W.A.G., and Z.R. wrote the paper. All the authors have discussed the results and wrote the paper together.

\section{Additional information}

Supplementary Information accompanies this paper at https://doi.org/10.1038/s41467018-04746-Z.
Competing interests: The authors declare no competing interests.

Reprints and permission information is available online at http://npg.nature.com/ reprintsandpermissions/

Publisher's note: Springer Nature remains neutral with regard to jurisdictional claims in published maps and institutional affiliations.

(c) (i) Open Access This article is licensed under a Creative Commons Attribution 4.0 International License, which permits use, sharing, adaptation, distribution and reproduction in any medium or format, as long as you give appropriate credit to the original author(s) and the source, provide a link to the Creative Commons license, and indicate if changes were made. The images or other third party material in this article are included in the article's Creative Commons license, unless indicated otherwise in a credit line to the material. If material is not included in the article's Creative Commons license and your intended use is not permitted by statutory regulation or exceeds the permitted use, you will need to obtain permission directly from the copyright holder. To view a copy of this license, visit http://creativecommons.org/ licenses/by/4.0/.

(C) The Author(s) 2018 